\title{
Rogeaulito: A World Energy Scenario Modeling Tool for Transparent Energy System Thinking
}

\section{Léo Benichou ${ }^{1 *}$ and Sebastian Mayr ${ }^{2}$}

${ }^{1}$ The Shift Project, Paris, France

2 Paris School of International Affairs, Sciences Po., Paris, France

\section{Edited by:}

Joni Jupesta, United Nations

University, Japan

Reviewed by:

Yi Zong, Technical University of Denmark, Denmark

Marco Aiello, University of Groningen, Netherlands

*Correspondence:

Léo Benichou, The Shift Project, 96

rue de la Victoire, Paris 75009 , France

e-mail: leo.benichou@

theshiftproject.org
Rogeaulito is a world energy model for scenario building developed by the European think tank The Shift Project. It's a tool to explore world energy choices from a very long-term and systematic perspective. As a key feature and novelty it computes energy supply and demand independently from each other revealing potentially missing energy supply by 2100. It is further simple to use, didactic, and open source. As such, it targets a broad user group and advocates for reproducibility and transparency in scenario modeling as well as model-based learning. Rogeaulito applies an engineering approach using disaggregated data in a spreadsheet model.

Keywords: energy model, energy systems, energy scenarios, scenario-planning, spreadsheet model, energy transition, bottom-up model

\section{INTRODUCTION}

Since the 1970s energy crisis, a series of unforeseen and highly visible events have brought energy issues again to the forefront of attention. These occurrences include geopolitical conflicts in the Middle East in the aftermath of the September 11 attacks, the BP oil spill in the Gulf of Mexico in 2010, a more difficult investment environment for energy infrastructure projects due to the ongoing financial crisis as well as the Fukushima Daiichi nuclear disaster in Japan in 2011. The latter led to a permanent closure of eight nuclear power plants in Germany, revisions of nuclear policies in Switzerland and Italy and an EU-wide stress test for nuclear power plants.

These events were coupled with more gradual systemic developments that have been taking place during the last two decades influencing world energy commodity markets and prices. These include climate change, fears about long-term oil capacity shortages, significant economic growth in Brazil, Russia, India, and China and the discovery and exploitation of non-conventional fossil fuels in North America.

While some of these occurrences and developments shed light on the current energy system's performance, they also point to the need for better world energy system analysis and for reconsidering alternative pathways to "business as usual." New forms of world energy scenario analysis are necessary to inform policy and decision-makers in a transparent, simple, and didactic way about potential uncertainty factors constraining world energy supply, main drivers affecting energy demand, and the dynamics of supply demand match in the mid and long-term. Finally, it would make them aware of underlying assumptions and how these can impact energy scenarios as well as the complex interdependencies, ideally including energy-environment and energy-economy links leading to better decision-making.
In this paper we present the Rogeaulito world energy scenario model, a free ${ }^{1}$ and open source tool designed to explore world energy choices with a very long-term and systematic perspective. It is a simple and transparent engineering spreadsheet model using disaggregated data and was developed by the European notfor-profit think tank The Shift Project. The Shift Project aims to promote a sustainable economy by guiding the decision-making processes of companies and public institutions through formulation and presentation of innovative and appropriate proposals built on scientific facts.

Rogeaulito's objective is to provide energy-related information in order to help shaping policy decisions. It solves the widespread contradiction observed in the literature between two methods: first, designing energy scenarios based on demand, and for which the required energy supply is determined. The underlying reasoning here is that when prices rise, it is possible to access more fuel resources and therefore provide it to consumers. Second, designing scenarios based on the acknowledgment of the imminent supply constraint, adapting accordingly the demand. In order to reconcile these two apparently contradictory viewpoints, Rogeaulito computes supply and demand independently from each other on the basis of distinct computations. As a result, it reveals a potentially missing energy supply (MES) between today and 2100 .

This paper consists of three sections. In the first section, we will briefly locate Rogeaulito in the landscape of energy models and then discuss the rationale of its key features. We will then describe the functioning of the tool in further detail and how the modeling process is operated. Finally, we will present potential uses and

\footnotetext{
${ }^{1}$ A full-fledged technical description of the tool and further related information are available on the website http://theshiftproject.org/this-page/rogeaulito. The tool itself is made available on request by contacting The Shift Project, 96 rue de la Victoire, 75009 Paris, France, Tel. (+33) 1762110 20, E-mail: communication@theshiftproject.org
} 
briefly sketch elements for effective use of Rogeaulito in public policy-making.

\section{ROGEAULITO IN THE ENERGY MODEL TAXONOMY AND RATIONALE OF KEY FEATURES}

Scenario-planning, emerged as a tool for leaders to allow storytelling about a variety of plausible long-term future occurrences or pathways in changing and uncertain environments (Chermack et al., 2001). In simple terms, a scenario (also called "narrative") is a "set of illustrative pathways" that indicates how "the future may unfold" (Ghanadan and Koomey, 2005). Usually an analysis combines an optimistic, a pessimistic, and a most likely scenario, generated in a participatory and interactive process. Another common technique is to identify the two most uncertain driving forces in the technological, social, political, or even economic environment and to plot them on two axes to develop four diverging scenarios each of which having both positive and negative aspects.

Scenario analysis in the energy sector mostly integrates scenarios with the help of an energy system model, which refers to a computer-based "mathematical description [...] of a real system and the ways that phenomenon occur within that system" with a focus on energy issues (van Beeck, 1999). The energy system models are "formulated using theoretical and analytical methods from several disciplines, including engineering, economics, operations research, and management-science" (Hoffman and Wood, 1975). As a consequence, a multitude of approaches, models, and techniques exist for multiple purposes leading to an overwhelming and diverse literature. Since comprehensive reviews of literature have been performed elsewhere (Jebaraj and Iniyan, 2006; Bhattacharyya and Timilsina, 2010; Varum and Melo, 2010), we will - in the limits of this paper - locate Rogeaulito's approach in the broad range of energy model types.

\section{ROGEAULITO IN THE LANDSCAPE OF ENERGY MODEL TYPES}

While all energy models potentially fulfill a decision-support function, each model has its own purpose entailing certain advantages and disadvantages. In the literature, many classifications of energy model types exist (Bahn et al., 2004; e.g., Hourcade et al., 1996; Herbst et al., 2012). van Beeck (1999) provides a quite comprehensive, literature-based classification along nine model characteristics such as purpose of model, model structure, analytical approach, and data requirements. Table 1 reproduces this classification, slightly adapted, and shows the respective values for Rogeaulito.

Please note that the list of values in the second column is not exhaustive. For concrete model examples with specific values, please refer to van Beeck (1999).

The purpose of an energy model refers to the type of scenarios that are built with the model. One can distinguish forecasting, exploring, backcasting scenarios, which reflect three ways of thinking, namely "probable, possible, and preferable," or in other terms "what will happen," "what can happen," and "what shall happen." Börjeson et al. (2006) further refines this typology by creating subgroups. For example, backcasting scenarios can either transform current system structures or optimize them by using quantitative models such as TIMES/MARKAL (Seebregts et al., 2001) or MESSAGE (Messner and Strubegger, 1995) or qualitative models such as regional planning. Similarly, explorative scenarios both include scenarios on external factors beyond the relevant actor's control (Randall and Wood, 2007) and strategic scenarios, incorporating policy measures at the hand of the user to cope with the issue at stake.

While Rogeaulito is a tool, which - a priori - does allow developing forecast, explorative, and backcasting scenarios, it does not do so by itself but leaves much of the work of variable setting as well as the matching of demand and supply to the user. The user-centered approach is mainly due to the slightly different main purpose of Rogeaulito, which is to reduce overconfidence in certain assumed energy futures as part of the macro-economic environment of countries and companies and send out early warning signals by revealing potentially MES in the long-term (see "Rogeaulito in the Energy Model Taxonomy and Rationale of Key Features" and "Modeling Principle of Rogeaulito" for more details on key feature and usages).

The terms "top-down" and "bottom-up" are analytical approaches and shorthand for aggregated and disaggregated models of demand and supply (Markandya and Halsnaes, 2001). While the former are typically developed by economists based on economic indices of prices and elasticities exploring macro-economic effects of a certain type of policy often using econometric methods, the latter are typically developed by engineers based on detailed descriptions of end-use and production technologies and cost structures (physical accounting). In addition to the inclusion of cost assessments, Rogeaulito possesses most of the advantages of a bottom-up model. For example, it allows exploring potential gains in efficiency from specific supply technologies and technological cost-optimization strategies. The lack of macro-economic behavioral feed-backs due to the exclusion of price mechanisms in the model structure makes Rogeaulito better suited to long-term "what-if" simulation analyses rather than to prediction (Hourcade et al., 1996). Furthermore, it is more effective in assessing the role of technological evolution to achieve a low-carbon economy. In the past years, hybrid models have tried to integrate bottom-up and top-down approaches and the distinction has become more and more blurred (Böhringer and Rutherford, 2008; Catenazzi, 2009; Sassi et al., 2010; Proença and St. Aubyn, 2013).

The analytical approach is closely linked to the degree of endogenization, which refers to the degree of incorporation of parameters within the model structure "so as to minimize the number of exogenous parameters" (van Beeck, 1999). While top-down approaches have a high degree of endogenization and are usually used for (short-term) forecasts, bottom-up engineering tools like Rogeaulito have a very low degree of endogenization and are usually used for "what-if" scenario development. Rogeaulito not only leaves the setting of many macro-variables, such as economic growth or ultimate recoverable fossil energy resources to the user, he or she can also describe the future values of variables in terms of evolution parameter and shape of the scenario curves.

All of this is done by means of a Excel spreadsheet (Grubb et al., 1993; Hourcade et al., 1996), a standard office software which is widely used and freely available in the OpenOffice version (cf. http://www.openoffice.org). While the term spreadsheet is also sometimes used to refer to modeling software packages, Rogeaulito is more like a "tool box," which includes a "reference model that 
Table 1 | Rogeaulito in the energy model taxonomy

\begin{tabular}{|c|c|c|}
\hline Characteristic & Values & Rogeaulito \\
\hline Purpose of energy model & $\begin{array}{l}\text { General: forecasting, exploring, backcasting } \\
\text { Specific: assessment of energy demand, energy supply, } \\
\text { impacts, integrated approach }\end{array}$ & $\begin{array}{l}\text { Revealing potentially missing energy supply } \\
\text { Forecasting, exploring, and backcasting (very user-driven) } \\
\text { Integrated approach allowing to match (and not to match) } \\
\text { global energy demand and energy supply; sub-model } \\
\text { computes global GHG emissions from primary energy } \\
\text { supply }\end{array}$ \\
\hline Analytical approach & Top-down or bottom-up & Bottom-up \\
\hline Modeling procedure & $\begin{array}{l}\text { Top-down: econometric, macro-economic, economic equilibrium } \\
\text { Bottom-up: optimization, simulation, physical accounting } \\
\text { (spreadsheet/toolbox) }\end{array}$ & Physical accounting (spreadsheet/toolbox) \\
\hline $\begin{array}{l}\text { Model structure: internal } \\
\text { assumptions and } \\
\text { external assumptions }\end{array}$ & $\begin{array}{l}\text { Degree of endogenization, description of non-energy sectors, } \\
\text { description end-uses, description supply technologies }\end{array}$ & $\begin{array}{l}\text { Very low degree of endogenization, exclusion of } \\
\text { non-energy sectors, very detailed description of } \\
\text { end-uses and supply technologies }\end{array}$ \\
\hline Geographical coverage & Global, regional, national, local, or project & Global \\
\hline Sectorial coverage & Energy sectors or overall economy & All sectors producing, transforming, or consuming energy \\
\hline Time horizon & Short, medium, long-term & Very long-term (until 2100) \\
\hline Data requirements & Qualitative, quantitative, monetary, aggregated, disaggregated & Quantitative, disaggregated \\
\hline
\end{tabular}

can easily be modified according to individual needs" (van Beeck, 1999).

\section{RATIONALE OF KEY FEATURES}

Rogeaulito was developed to address two major shortcomings observed in world energy scenario modeling literature. These are the ideologically or politically motivated matching of energy supply to demand in energy scenarios and the high degree of opacity and irreproducibility of many underlying energy models.

\section{Matching very long-term supply and demand: Neo-classicists vs. Neo-Malthusians}

In practice, scenarios often begin by modeling demand and match it with the necessary level of supply possibly using prices as an adjustment mechanism. This may often be on the basis of socioeconomic considerations or aspirations, in particular the right of countries to develop (cf. United Nations General Assembly resolution 41/128). Examples of this common practice can be found in the World Energy Outlook (IEA, 2012a) using the World Energy Model for a time horizon until 2035 or in Sambo (2008), who describes teaching methods of the International Atomic Energy Agency (IAEA) applying IAED energy models MAED and MESSAGE as energy demand and supply models on a national scale over a 30-year-period. While this approach is widely applied, it may be less useful for a longer time horizon due to the finiteness of fossil fuel-based energy supply in the long-term.

In essence, the modeling practice is contested theoretically by the long-standing debate between Neo-classicists and NeoMalthusians on the scarcity of natural sources and the question to what extent free market and growth do resolve or aggravate this universal problem. While Neo-classicists (e.g., Walras, 1954) argue that high prices of scare resources lead to the substitution of other, less scarce resources in production, more efficient operations and use capital, technological innovations, increase of technically and economically recoverable resources (Matthaei, 1984; Grubb et al., 1993) and eventually a de-coupling of economic activity and resource consumption (Cleveland et al., 1984), as it happened in the case of energy in high income countries after the energy crisis since the 1970s (e.g., Huang et al., 2008) NeoMalthusians contest this view. Although Neo-Malthusians, based on the work of Thomas Robert Malthus (1766-1834), agree that natural resources, as physical goods, are inherently scarce by definition (Boulding, 1966; Barnett and Morse, 1967), they discover a problem in the exponential growth in population and consumption levels, which are not in congruence with the arithmetical (if at all) growth of natural resources leading to "Limits to growth" (Meadows et al., 1972) or bell-shaped petroleum production curves (Hubbert, 1956). In their argumentation, Neo-Malthusians often support their paradigm additionally by the Second Law of Thermodynamics pointing out that matter/energy moves from low entropy to high entropy, while low entropy material is scarce (Georgesçu-Roegen, 1971; Rifkin and Howard, 1980).

Today, the debate and its consequences on the modeling practice appears to be more acute than ever (cf. Krautkraemer, 2005). While the recently observed stagnant world oil production in the face of persistent and large oil price increases supports the NeoMalthusian view, Neo-classicists gain support from the discovery of non-conventional fossil fuels such as tar sands or shale gas in North America (Maugeri, 2012) and refer to the increasing use and potential of renewable energy in global power generation and beyond (McCrone et al., 2013). The topic has also entered the policy arena and is more and more discussed independently from the climate-change debate. For example, both the famous Hirsch report in the United States (Hirsch et al., 2006) and a recent study 
by the IMF assess the social, economic, and political consequences of peak oil (Kumhof and Muir, 2012).

Matching long-term energy supply to demand and vice-versa thus largely depends on the underlying economic approach in the modeling process and the respective assumptions made in the formalization of the demand and supply side of the world energy system. Against this background, Rogeaulito proposes a neutral and distinct modeling of energy demand and supply. It describes physical variables on the energy supply side subject to constraints (in terms of extractable stocks of fossil fuels and uranium, areas available for biomass cultivation, etc.), a primary energy demand from the "consumer-driven" point of view (derived from the final demand of vehicles, buildings, etc., average consumption per unit and all extrapolated over time) and makes potential long-term missing energy supplies visual and transparent (as for an example using the above-mentioned approach, with a focus on the aviation sector, see Nygren et al., 2009).

\section{Reproducibility, transparency, and learning}

In addition to the formal modeling approach, Rogeaulito tries to address repeated calls from the broader scientific community (Schwab et al., 2000; Barnes, 2010; Stodden, 2010; Hanson et al., 2011; Peng, 2011; Ince et al., 2012) and from the science-policy interface (European Commission, 2011; International Council for Science, 2011) to make model source code and data of energy model runs publicly accessible. These calls are based on the scientific goal to increase transparency and reproducibility, which would ultimately allow verifying externally results of energy models. Verification represents "the process of review that ensures that the data are error-free, assumptions are discoverable, and the mathematical model operating on the data produces the intended result" (DeCarolis et al., 2012). Moreover, reproducibility lends credibility to the intellectual effort, opens the possibility of learning about the model structure (assumptions, cause-effects, etc.) and a precondition of scientific progress. This goes mostly along with a low degree of complexity, as simple models are easier to understand, persuasive, and more amenable to peer review of underlying data and assumptions (Craig et al., 2002; Laine et al., 2007).

The issues of open source and simplicity are closely related to issues of learning as a wide range of decision-support functions are attributed to energy models. In particular, they have an important cognitive function by allowing analysts and decision-makers to explore elements in the system that the model tries to represent. This gives rise to a so called model-based reasoning (Frigg and Hartmann, 2009). Hughes (1997) hypothesizes on this process in further detail: elements of the physical world are represented by elements of the model leading us to demonstrate theoretical conclusions and interpretations if we are to make predictions. It is evident that such benefits are particularly pronounced if the energy model is accessible, transparent, and easy to use.

Although the possibility of reproduction and verification of model results by external parties constitutes an essential part of the scientific method, it is rare practice in the field of energy modeling so far. Only very few (but very visible and largely cited) open source energy models exist such as the integrated assessment model DICE (Nordhaus and Boyer, 2000), or AIM (Kainuma et al., 1999), an integrated energy model, which was developed mainly to examine global warming response measures in the Asian-Pacific region. Besides open source code and date, these software packages are also license-free, non-commercial, and give permission to redistribute. This rather broad understanding of open source is based on DeCarolis et al. (2012).

Rogeaulito addresses these issues by being publicly available and providing cost-free access to the spreadsheet model. Furthermore, the model can be freely redistributed and a how-to-use-guide and a technical model description are made available (see text footnote 1). Finally, as a disaggregated bottom-up model, it opens up the black box inherent to economic models providing a transparent view on the influence of variables on the final result. The independent modeling of supply and demand without price mechanisms and economic loops helps clarify and simplify the fields. Rogeaulito is a model, which is relatively easy to use as it comes in a Microsoft Excel spreadsheet format and with a user-friendly design.

All of this reflects Rogeaulito's philosophy, which is simplifying the model and putting it into the user-driven setting of the different variables to describe energy demand, supply, and conversion. This triggers learning and exchange toward a better understanding of sub-sectors and variables of the demand, supply, and conversion sectors in an energy system. The user learns also about the link between the assumptions made and the results and handling of a model in general. Most significant variables likely to shape the future energy demand and supply need to be identified and described. This learning opportunity may be particularly meaningful when the modeling process is reiterated. This can happen when the tool reveals that supply does not match demand in the long-term. As a consequence, the user may have to revise his or her assumptions and choices on the future energy system by exploring upper scenarios of supply and lower scenarios of demand and the particular roles of policy measures, instruments, and technology.

\section{MODELING PRINCIPLE OF ROGEAULITO}

As for now, Rogeaulito is designed for modeling energy scenarios at a global level and with a time range from 2010 to 2100 . The description of all variables is made on a yearly interval basis. To define a starting point of variable size before scenarios are developed, the model uses historical data from the widely used IEA energy balance database (IEA, 2012b). In Rogeaulito, historical data covers years from 1990 to 2009. Similarly, historical data for physical variables has been collected from various sources and the physical description data has been consolidated to make them consistent with IEA balances. A physical variable represents a part of the energy system, either on the demand or supply side, such as average fuel consumption per kilometer per vehicle or installed PV capacity. At heart, the modeling process is then done by setting the future evolution of many physical variables through predefined formal mathematical models.

The future evolution is modeled by choosing an evolution type among many possibilities (linear, exponential, gauss curves, sigmoid, etc.) and entering parameters for the curve's function, which already comes with Rogeaulito. This leads to an output for each variable in 2100 , which Rogeaulito automatically aggregates through additions and multiplications. For example, the future evolution of car ownership rate (variable) can be set using a linear 
curve (shape) with a growth rate of 1 vehicle per 1000 capita per year (evolution parameter). In the resulting scenario there would then be an increase from 125 vehicles per 1000 capita in 2009 to 217 vehicles per 1000 capita in 2100 .

It is obvious that the manual assessment of the future evolution of these variables requires detailed and extensive knowledge from the model user. This applies also to the identification of key variables likely to influence the world energy supply and demand in the next decades. Moreover, there may be "invisible correlations" between the different variables describing the energy system. For instance, steel consumption per capita is somehow related to installed capacity of wind power, as wind turbines are made of steel.

The modeling process is made up of four independent modules, namely the demand, supply, conversion, and core module. The user defines future evolution of variables in each of these modules starting with primary energy supply (energy resources available in nature), then final energy demand (total energy consumed by end users), the conversion of final energy demand into primary energy and eventually matching demand and supply in a reiterated process, if necessary. Figure 1 illustrates this process.

\section{DEMAND MODULE}

In the demand module the evolution of the demand in final energy from the different sectors (transports, buildings, etc.) is modeled. A sectorial breakdown of the demand is proposed to allow a purely physical formal description. The sectors considered are Buildings, Industry, Transport, Agriculture and Fishing, and Others and Non-energy Uses. Each sector can be split into several sub-sectors (Table 2) in accordance with IEA (2011). Eventually, demand is described in terms of evolutions of social aspiration (car ownership per capita, residential area per capita, steel consumption per capita, etc.) and of energy efficiencies (car fuel consumption, energy needed per square meter in buildings, energy needed to produce one ton of steel, etc.).

\section{SUPPLY MODULE}

The supply module allows modeling of the supply's evolution (expressed in primary energy). Seven major primary energy resources, split into their corresponding sub-resources, are to be set manually under physical considerations (Table 3 ). The purpose is to define the evolution of the energy production of each one of these energy carriers. Three main groups can be distinguished. First, fossil fuels (Oil, Gas, Coal), for which Rogeaulito provides a set of logistic curves to illustrate the typical production profile and the finite aspect of the Ultimate Recoverable Resources (URR) that we can actually extract from the ground. Usually long-term supply curves of fossil fuel resources are bellshaped (Hubbert, 1956). Second, power plants (Nuclear, Renewables for electricity), whose evolution can be set by indicating the installed capacity, the load factor, and the energy production. Third, other primary energy resources (other renewables, others non-renewable), whose evolution can also be set directly with the energy production.

\section{CONVERSION MODULE}

The Conversion Module is a model of the energy sector that stands in between the final demand and the primary energy demand. It makes a link between the two by taking account of the conversion and distribution losses in all extraction, transformation, and

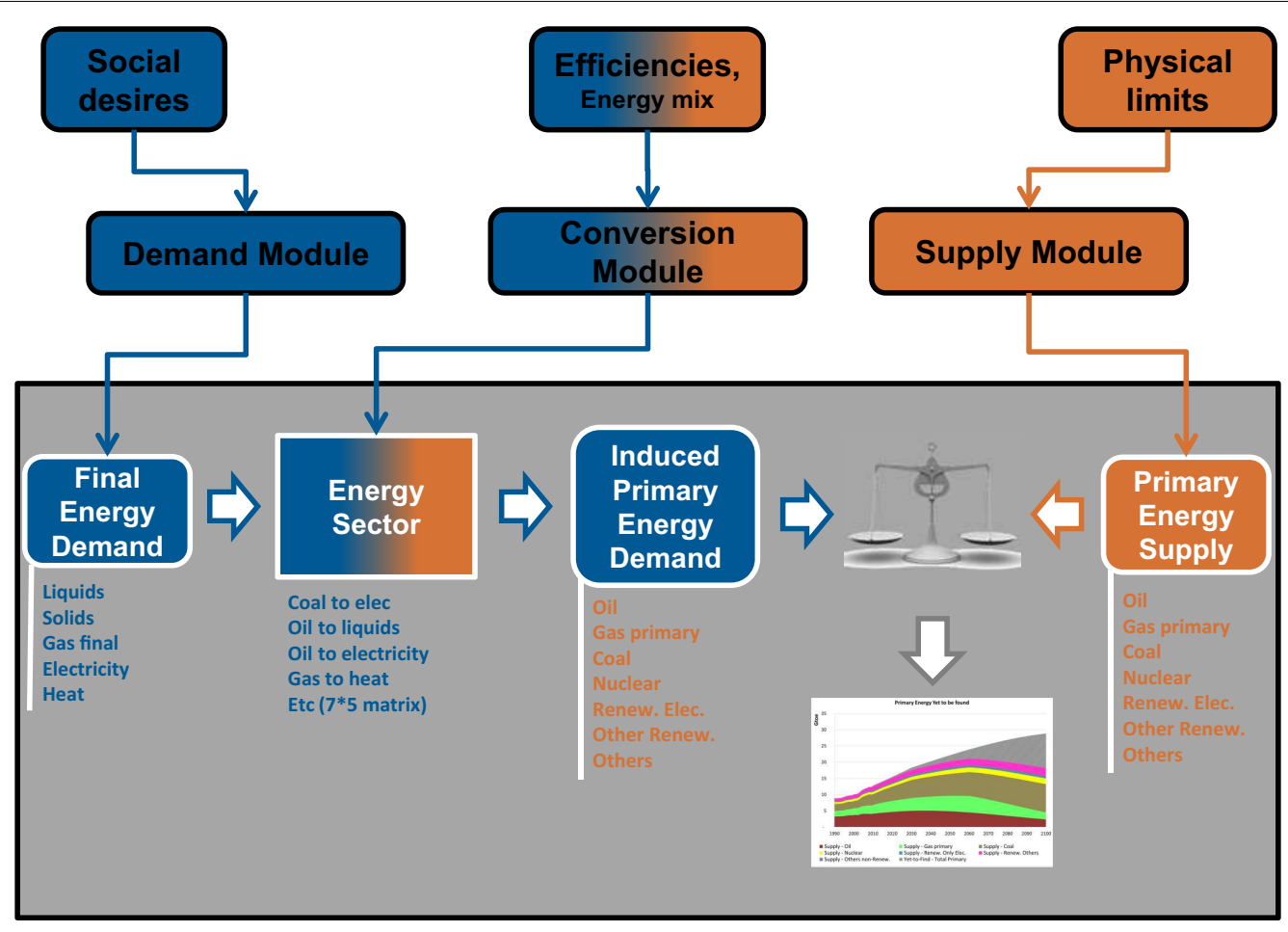

FIGURE 1 | Rogeaulito's modeling principle and modules organization. 
Table 2 | Sectorial breakdown and operationalization of variables in the demand module.

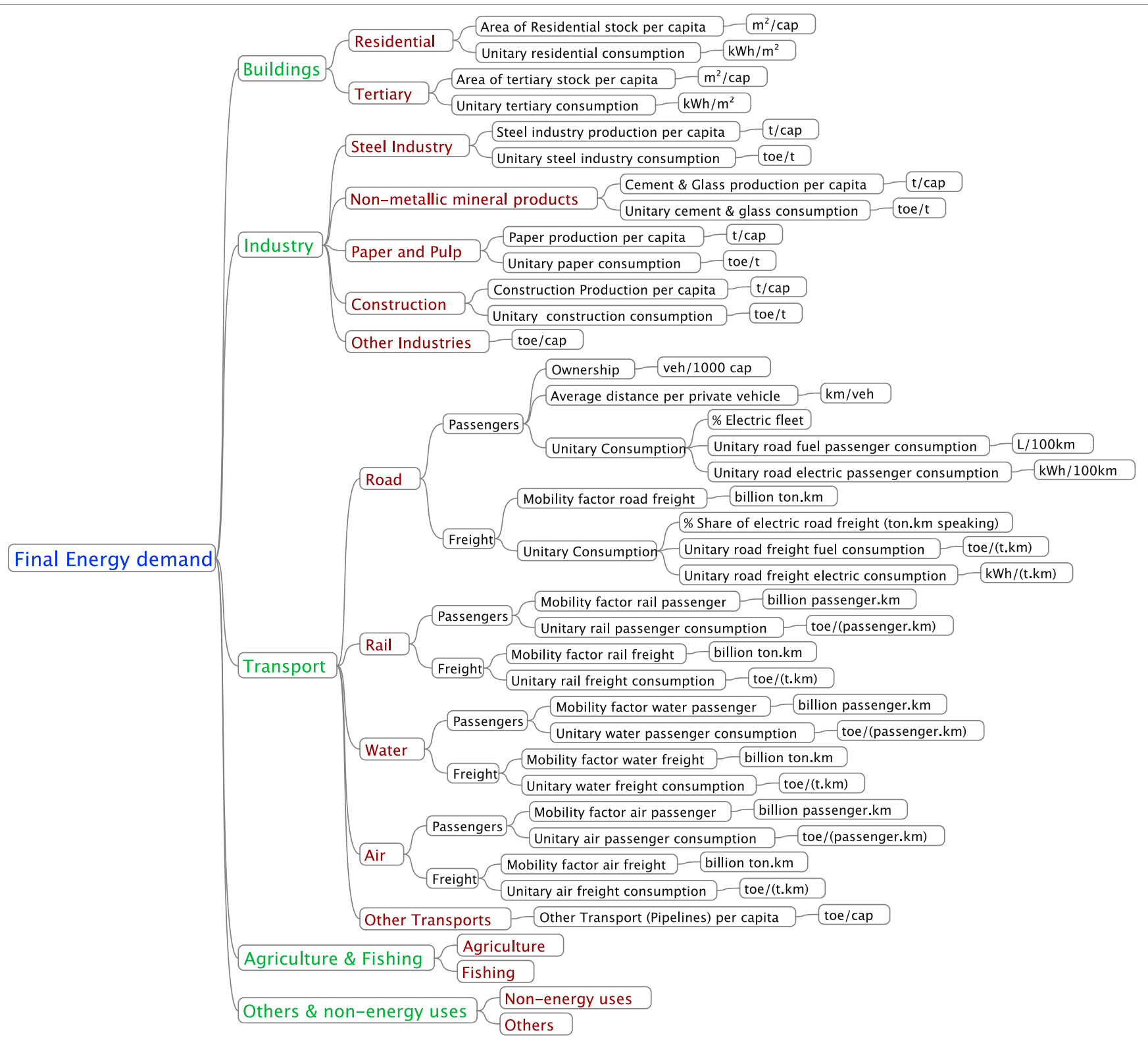

transportation units lying in between the primary energy demand and final demand (energy consumed) as well as auto-consumption of the energy sector (Figure 2). Concretely, the set of variables set in this module are intended to convert a desired final energy demand vector into an equivalent primary energy demand so as to compare it with the primary supply vector within the same referential. The objective of the conversion module is to allow an exploration of the consequences of a variation of these variables on a future modeled energy system.

In short, the hypotheses embedded in the conversion module impact the way final energy in the projections is re-converted into primary energy supplies. The two main groups of variables at stake are related to the allocation of energy carriers and the efficiency of their transformations. Rogeaulito allows the external manual setting of the evolution of the conversion efficiencies in transformation units (in power plants, refineries, etc.) and of the origin of each final energy (electricity mix, etc.) as illustrated in greater detail in Table 4.

\section{CORE}

In the final module, the core, a scenario of demand, supply, and conversion is imported from each module. The outputs from the conversion module are used to convert the demand in final energy into an induced demand in primary energy. Then, this induced demand can be compared with the supply and an eventual MES over a time period from 2010 until 2100 (Figure 3). If the demand does not match supply, the process can be reiterated by adjusting the variable settings in the supply, demand, or conversion module. 
Table 3 |The primary energy breakdown and operationalization of variables in the supply module.
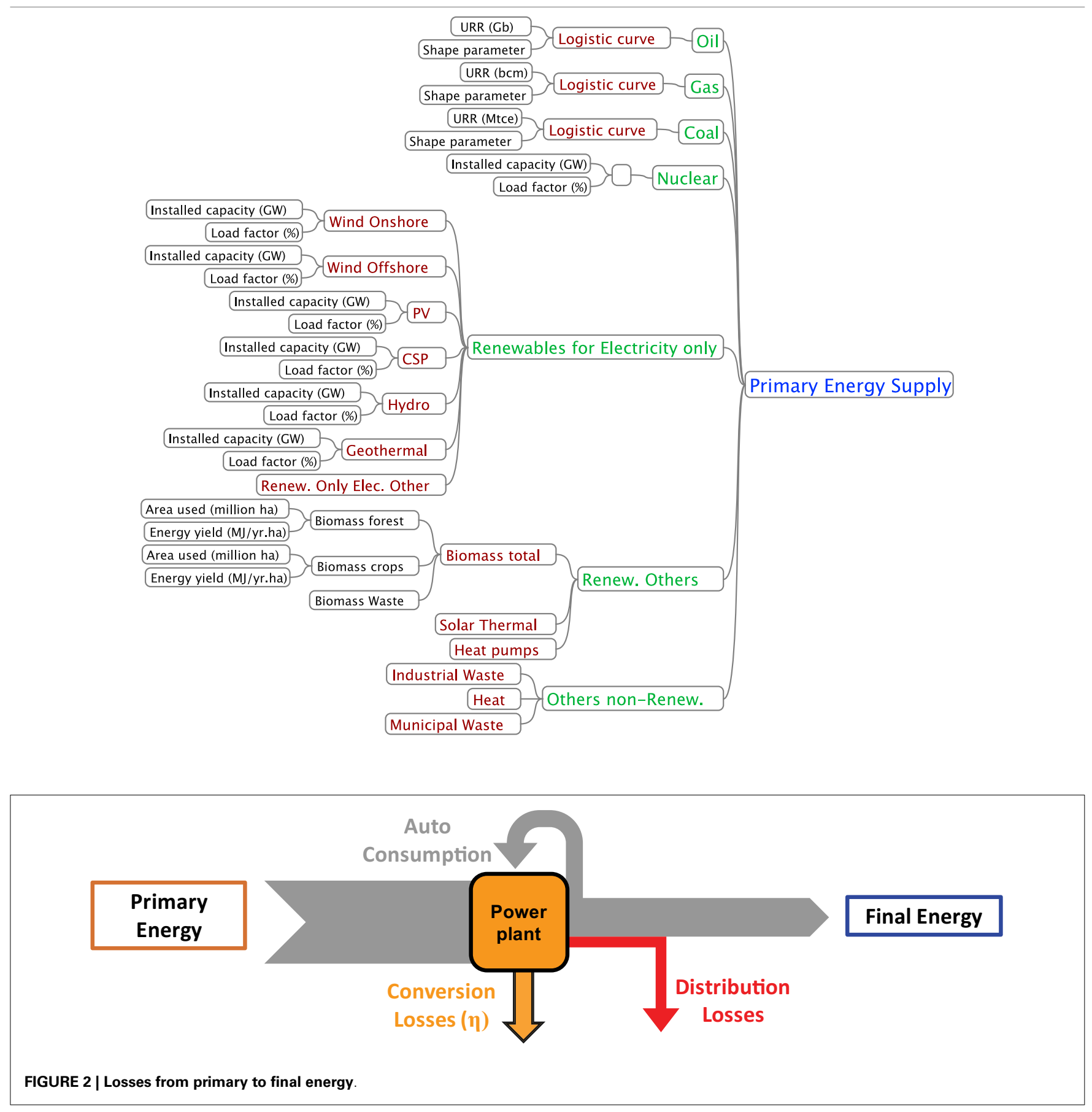

Table 4 | The conversion variables to be set in the conversion module

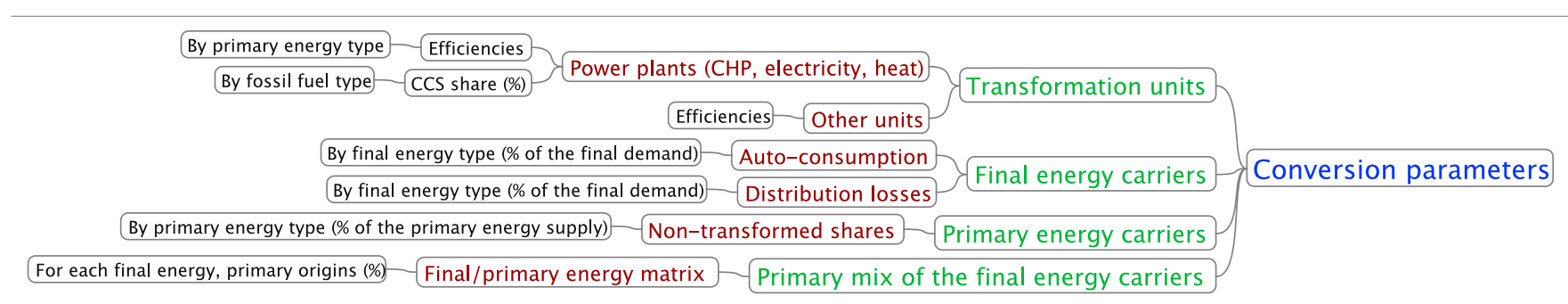




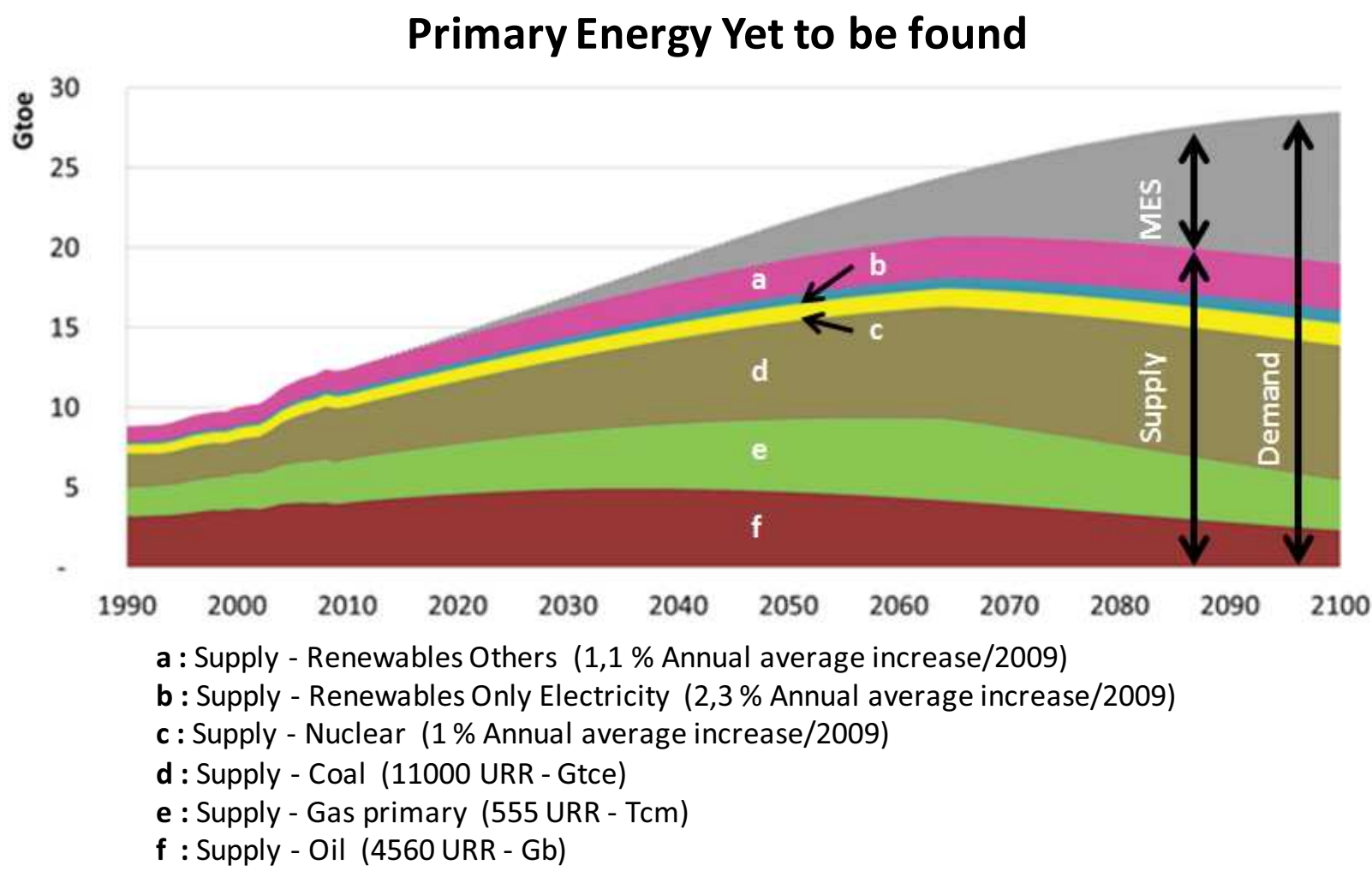

FIGURE 3 | Missing energy supply (MES).

By convention, the MES cannot be inferior to zero. In case MES is inferior to zero, it is automatically set to zero.

\section{USAGES AND EFFECTIVENESS}

Apart from educational benefits outlined in the first section and having a reference scenario for the future, the literature attributes a number of theoretical and cognitive benefits to the use of the energy scenario method and scenario tools like Rogeaulito. For example, the scenario method can help planners make better sense of their external environment, spot early warning signals, reduce overconfidence in one particular future and refine perceptions of existing or emerging problems and corresponding problem-solving strategies. When the scenario method is used in combination of participatory methods to generate and collect ideas, knowledge, and views regarding possible futures, it can also help out conflicts between stakeholders, mobilize action, and trigger organizational and institutional change (Lempert et al., 2003; Volkery and Ribeiro, 2009).

While Rogeaulito does not exert influence on the process of scenario development, the tool intends to fulfill all planning-related functions. It thus sensitizes planners to think about the long-term evolution of the world energy system by ringing an early bell concerning wrong assumptions and perceptions of the future through revelation of potentially missing energy. Furthermore, it allows assessing the effects of technology-related changes on the energy system (as part of problem-solving strategies) as well as testing other scenarios from other studies. However, the benefits of these usages are only fully reaped if the results of the tool are appropriately absorbed by the institutional capacities and translated into the strategy of the user's organization.

\section{USAGES}

\section{Revealing missing energy supply and matching energy supply and} demand

To make use of the tool's key feature, reference scenarios of demand and supply are developed independently from each other. In case this reveals a MES, a second step can be enchained, as part of which the user adjusts assumptions and variable sizes in the variables setting until demand and supply match. In addition, the user may not only want to find any match but identify the "best match" of all possible combinations. Such "best match" would take account of technological potentials and limits on the supply side (for example of renewable energies), the social and political acceptance of consumption cuts, certain technology, and energy preferences (while costs remain outside of the tool's scope), politics and institutions and any further variables that deem relevant to the user. This step thus resembles the development of a backcasting scenario by finding not only $a$ variable setting but the best one with the highest social and political acceptance, most likely to be implemented.

\section{Revealing counterparts}

The Rogeaulito framework enables to reveal the counterparts of the evolution of variables as part of the scenario building. 
By "counterpart" we mean the necessary conditions that make the evolution of a variable possible, which basically follows the "what-if" principle.

There can be two ways of using the counterpart feature. In the first way, the evolution of a variable is directly converted into a physical counterpart, which stands as an output set by the user. For example, biomass for energy requires dedicated land use. By setting the yield variable $(\mathrm{MJ} / \mathrm{ha} / \mathrm{yr})$ in Rogeaulito the required land use counterpart at base is "automatically" defined. The second way combines the first way and the MES match process described above. For example, to set an increasing car ownership and a fixed distance traveled by car as part of a future evolution description (all that matching with a given fuel production for energy demand for car transportation), the necessary counterpart revealed would be that the average car efficiency has to improve at a certain pace.

More broadly, as there are no built-in loops or feed-backs between variables in the model, the prospective approach in Rogeaulito framework makes you think not only about drivers that are likely to frame the evolution of variables in the system but also on relations between variables (e.g., car fleet evolution is likely to have a link with steel production), which contributes to shaping a critical mindset toward a model.

\section{Assessment of technology-related effects}

Finally, as another potential usage, Rogeaulito allows exploring what-if scenarios, either as part of the matching supply and demand process or independently. As outlined above, engineering models such as Rogeaulito are predestinated for exploring technology-related changes from a long-term perspective. Typical questions to explore could revolve around effects of certain technology-related measures on energy supply or demand such as the improvement of car efficiency or refurbishment of buildings or the increase of efficiency of photovoltaic solar panels or development and extraction of shale gas in Europe.

\section{ELEMENTS FOR EFFECTIVE USE IN PUBLIC POLICY-MAKING}

Although there is much acclaim of the usefulness of the scenario method in the planning process, its impact and the factors governing its effectiveness remain largely an empirical question. While some work has been carried out on evaluating the predictive power of energy forecasts, with mixed results (Bentzen and Linderoth, 2001; Craig et al., 2002), and on recording the number of runs of certain energy-climate models and scenarios (Nakicenovic and Swart, 2000; Hanaoka et al., 2006) such work has a different evaluative focus and does not identify the factors leading to an effective use of scenarios.

While Rogeaulito can be used quite flexibly, its main purpose is - besides educative purposes - to reduce overconfidence in certain long-term energy futures and provide early warning indicators signaling a shift toward a certain kind of future and narrowing down uncertainties in the macro environment. It makes aware of potential adjustment needs and stimulates the development of new plans, strategies, and policies. As such, Rogeaulito's effectiveness depends on how much users translate the results of the analyzed scenarios into energy-related strategies in their private or public policy organization. Much of this depends on the capacity of the organization to absorb these results. Unfortunately, the number of studies examining such questions empirically is very low.

In a major attempt Volkery and Ribeiro summarized 52 sources of the still nascent evaluative scenario literature and cross-checked their preliminary findings with results from a scenario practitioners and policy-makers workshop. Although there are only a handful of studies examining the impact of scenario building on an organization's performance empirically, some broad lines can be set. The authors confirm that scenario-planning can lead to effective outcomes in terms of individual learning while learning usually requires a longer time when the results question core belief systems of relevant actors (Sabatier, 1988). This points to the importance of participation in the scenario development phase as participation creates not only consensus but also trust in sources and scenario developers, which is a critical factor for making organizational actors implement them (Ketokivi and Castañer, 2004). This stands in contrast with government practices, as they often outsource forward-looking analysis. Moreover, scenario-planning in the public sector differs to scenario-planning in the private sector in the heterogeneous nature of objectives and interests of governments and the lack of one single client. Policy-makers also have different time horizons than scenario planners and very different attention foci as they tend to follow established routines. These factors make scenario-planning in the public sector difficult and policy-makers tend to execute scenarios in a rather ad hoc and isolated manner and as indirect decision-support in early phases of the policy cycle such as agenda-setting and issue-framing (Volkery and Ribeiro, 2009).

On the basis of these insights, several elements are and can be identified for the effective use of Rogeaulito. First, the tool has real potential to contribute to the improvement of learning processes of individuals or groups. In addition, Varum and Melo (2010) find a consensus in the literature that the use of the scenario method leads to an improvement of the decision-making process and the identification of new issues and problems, which an organization may have to face in the future. Second, the inclusion of potentially relevant actors for the policy design and implementing phase during the scenario development process is as important as the scenario product itself. This requires some preliminary knowledge about which institutions and politics could potentially hinder or facilitate certain paths (Nilsson et al., 2011). The heterogeneous interests and objectives of these institutional actors require flexible and adaptive scenario formats and processes (Volkery and Ribeiro, 2009). In order to "translate" qualitative data from the participatory process into quantitative modeling input, Walz et al. (2007) consider the detailed documentation of this process a "crucial step." This in turn points indirectly to the important role of the scenario modeler in the process. Third, in case the tool shall be used in public policy-making its decision-support may be most effective in early phases of the policy cycle such as issue-framing and agenda-setting, as they are less formalized. Finally, in the absence of stable institutional settings and organizational capacities to absorb the results of the scenario studies (e.g., through regular governmental foresight studies), a minimum of governance conditions for scenario-planning need to be ensured. This entails at least a follow-up as well as a clear role and purpose of the scenario study within the decision-making process (Volkery and Ribeiro, 2009). 


\section{CONCLUSION}

An ever increasing unpredictability in the world energy system and unsustainable uses of energy shed light to the need for reconsidering alternative pathways to "business as usual" and new forms of world energy system analysis. Rogeaulito is a world energy scenario model, a simple, didactic, and user-driven open source tool, which computes supply and demand on the basis of distinct computations revealing potential missing energy supply until 2100. By doing so, the tool aims to reduce overconfidence in certain energy futures as part of the macro-economic environment of countries and companies and sends out early warning signals. As such, it may serve as a learning platform on the global energy system and, we hope, spur interest in the decision-making field.

In its current state of development, the model now deserves further refinement and the development of a cost module to allow the evaluation of investment costs and optimization of scenarios. Such global scenarios have already been developed and translated into model outputs and will be described further at a later stage. Moreover, a geographical refinement of the tool will allow differentiating and comparing the evolution of various world regions or countries with each other.

\section{AUTHOR CONTRIBUTIONS}

Léo Benichou has been the The Shift Project's expert on energy systems and energy scenario analysis and Rogeaulito project leader for almost 3 years. He did all conceptual work. Sebastian Mayr designed and drafted the article and carried out related complementary research.

\section{ACKNOWLEDGMENTS}

We acknowledge the early vision of Bernard Rogeaux for the missing energy supply paradigm, as well as the help of EDF R\&D during several phases of the project: François Cattier, Christophe Marchand, and Prabodh Pourouchottamin. We acknowledge the significant contributions of Jean-Marc Jancovici, Cédric Ringenbach, Benoit Lemaignan, and Olivier Rech to the model framework, and the careful work of all the students who got involved in the project: Gaëlle Le Treut, Marie-Pierre Meillan, Samuel Waterhouse, Bastien Praz, Joseph Hajjar, Damaris Franco, and last but not least Aurélien Schuller. We acknowledge support from The Shift Project funding members.

\section{REFERENCES}

Bahn, O., Haurie, A., and Zachary, D. S. (2004). Mathematical Modeling and Simulation Methods in Energy Systems. Groupe d'études et de recherche en analyse des décisions. Montréal: HEC Montréal.

Barnes, N. (2010). Publish your computer code: it is good enough. Nat. News 467, 753-753. doi:10.1038/467753a

Barnett, H. J., and Morse, C. (1967). Scarcity and Growth: The Economics of Natural Resource Availability. Baltimore: Resources for the Future Press.

Bentzen, J., and Linderoth, H. (2001). Has the Accuracy of Energy Demand Projections in the OECD Countries Improved Since the 1970s? Working Paper No. 01-5. Aarhus School of Business, Department of Economics. Aarhus.

Bhattacharyya, S. C., and Timilsina, G. R. (2010). A review of energy system models. Int. J. Energy Sector Manage. 4, 494-518. doi:10.1108/17506221011092742

Böhringer, C., and Rutherford, T. F. (2008). Combining bottom-up and top-down. Energy Econ. 30, 574-596. doi:10.1016/j.eneco.2007.03.004

Börjeson, L., Höjer, M., Dreborg, K.-H., Ekvall, T., and Finnveden, G. (2006). Scenario types and techniques: towards a user's guide. Futures 38, 723-739. doi:10.1016/j.futures.2005.12.002
Boulding, K. E. (1966). “The economics of the coming spaceship earth," in Environmental Quality in a Growing Economy: Essays from the Sixth RFF Forum, ed. H. Jarrett (Baltimore: Resources for the Future Press), 3-14.

Catenazzi, G. (2009). Advances in Techno-economic Energy Modeling: Costs, Dynamics and Hybrid Aspects, Dissertation, ETH, Zürich.

Chermack, T. J., Lynham, S. A., and Ruona, W. E. A. (2001). A review of scenario planning literature. Futures Res. Q. 17, 7-31.

Cleveland, C. J., Costanza, R., Hall, C. A. S., and Kaufmann, R. (1984). Energy and the U.S. economy: a biophysical perspective. Science 225, 890-897. doi:10.1126/ science.225.4665.890

Craig, P. P., Gadgil, A., and Koomey, J. G. (2002). What can history teach us? A retrospective examination of long-term energy forecasts for the United States. Annu. Rev. Energy Environ. 27, 83-118. doi:10.1146/annurev.energy.27.122001. 083425

DeCarolis, J. F., Hunter, K., and Sreepathi, S. (2012). The case for repeatable analysis with energy economy optimization models. Energy Econ. 34, 1845-1853. doi:10.1016/j.eneco.2012.07.004

European Commission. (2011). Final Report of the Advisory Group on the Energy Roadmap 2050. Summary Record of the PRIMES Peer Review Meeting. Results of the Public Consultation on the Energy Roadmap 2050. SEC2011/1569. Brussels.

Frigg, R., and Hartmann, S. (2009). Models in Science [WWW Document]. Stanford Encyclopedia of Philosophy. Available at: http://plato.stanford.edu/archives/ sum2009/entries/models-science/ [accessed 8, 11, 13].

Georgesçu-Roegen, N. (1971). The Entropy Law and the Economic Process. Cambridge: Harvard University Press.

Ghanadan, R., and Koomey, J. G. (2005). Using energy scenarios to explore alternative energy pathways in California. Energy Policy 33, 1117-1142. doi:10.1016/j. enpol.2003.11.011

Grubb, M., Edmonds, J., ten Brink, P., and Morrison, M. (1993). The costs of limiting fossil-fuel CO2 emissions: a survey and analysis. Ann. Rev. Energy Environ. 18, 397-478. doi:10.1146/annurev.eg.18.110193.002145

Hanaoka, T., Kainuma, M., Kawase, R., and Matsuoka, Y. (2006). Emissions scenarios database and regional mitigation analysis: a review of post-TAR mitigation scenarios. Environ. Econ. Policy Stud. 7, 367-389.

Hanson, B., Sugden, A., and Alberts, B. (2011). Making data maximally available. Science 331, 649-649. doi:10.1126/science.1203354

Herbst, A., Toro, F. A., Reitze, F., and Jochem, E. (2012). Introduction to energy systems modelling. Swiss J. Econ. Stat. 148, 111-135.

Hirsch, R. L., Bezdek, R., and Wendling, R. (2006). Peaking of World Oil Production: Impacts, Mitigation and Risk Management. Washington, DC: Nova Science Pub Inc.

Hoffman, K. C., and Wood, D. O. (1975). Energy system modeling and forecasting. Annu. Rev. Energy 1, 423-453. doi:10.1146/annurev.eg.01.110176.002231

Hourcade, J.-C., Richels, R., Robinson, J., Chandler, W., Davidson, O., Finon, D., et al. (1996). "Estimating the costs of mitigating greenhouse gases," in Climate Change 1995, Economic and Social Dimensions of Climate Change, Contribution of Working Group III to the Second Assessment Report of the Intergovernmental Panel of Climate Change, eds J. P. Bruce, H. Lee, and E. F. Haites (Cambridge: Cambridge University Press), 263-296.

Huang, B.-N., Hwang, M. J., and Yang, C. W. (2008). Causal relationship between energy consumption and GDP growth revisited: a dynamic panel data approach. Ecol. Econ. 67, 41-54. doi:10.1016/j.ecolecon.2007.11.006

Hubbert, M. K. (1956). Nuclear energy and the fossil fuel. Drilling and production practice. Conference Paper, 56-007. San Antonio, TX: American Petroleum Institute.

Hughes, R. I. G. (1997). Models and representation. Philos. Sci. 64, S325-S336. doi: $10.1086 / 392611$

IEA. (2011). World Energy Outlook 2011. Paris: OECD Publishing.

IEA. (2012a). World Energy Outlook 2012. Paris: OECD Publishing.

IEA. (2012b). World Energy Statistics and Balances. Available at: http://data.iea.org Ince, D. C., Hatton, L., and Graham-Cumming, J. (2012). The case for open computer programs. Nature 482, 485-488. doi:10.1038/nature 10836

International Council for Science. (2011). Statutes and Rules of Procedure [WWW Document]. Available at: http://www.icsu.org/publications/statutes-policies/ statutes-procedure/Statutes in English [accessed 8, 11, 13].

Jebaraj, S., and Iniyan, S. (2006). A review of energy models. Renew. Sust. Energy Rev. 10, 281-311. doi:10.1016/j.rser.2004.09.004

Kainuma, M., Matsuoka, Y., and Morita, T. (1999). Analysis of post-Kyoto scenarios: the Asian-Pacific integrated model. Energy J. 20, 207-220. 
Ketokivi, M., and Castañer, X. (2004). Strategic planning as an integrative device. Adm. Sci. Q. 49, 337-365.

Krautkraemer, J. A. (2005). Economics of Natural Resource Scarcity: The State of the Debate. Resources for the Future. Discussion Paper 05-14. Washington, DC.

Kumhof, M. M., and Muir, D. (2012). Oil and the World Economy: Some Possible Futures. Working Paper WP/12/256. Washington, DC: International Monetary Fund.

Laine, C., Goodman, S. N., Griswold, M. E., and Sox, H. C. (2007). Reproducible research: moving toward research the public can really trust. Ann. Intern. Med. 146, 450-453. doi:10.7326/0003-4819-146-6-200703200-00154

Lempert, R. J., Popper, S. W., and Bankes, S. C. (2003). Shaping the Next One Hundred Years: New Methods for Quantitative, Long-Term Policy Analysis. Santa Monica, CA: Rand Corporation.

Markandya, A., and Halsnaes, K. (2001). "Costing methodologies," in Climate Change 2001: Mitigation. Contribution of Working Group III to the Third Assessment Report of the Intergovernmental Panel on Climate Change IPCC, eds B. Metz, O. Davidson, R. Swart, and J. Pan (Cambridge: Cambridge University Press), 451-498.

Matthaei, J. (1984). Rethinking Scarcity: Neoclassicism, NeoMalthusianism, and NeoMarxism. Rev. Radic. Polit. Econ. 16, 81-94. doi:10.1177/ 048661348401600204

Maugeri, L. (2012). Oil: The Unprecedented Upsurge of Oil Production Capacity and What It Means to the World. Discussion Paper 2012-10, Belfer Center for Science and International Affairs, Harvard Kennedy School. Cambridge, MA.

McCrone, A., Usher, E., Sonntag-O'Brien, V., Moslener, U., and Grüning, C. (2013). Global Trends in Renewable Energy Investment 2013 [WWW Document]. Available at: http://fs-unep-centre.org/publications/ global-trends-renewable-energy-investment-2013 [accessed 8, 11, 13].

Meadows, D. H., Meadows, D., Randers, J., and Behrens, W. W. III. (1972). The Limits to Growth. A Report for the Club of of Rome's Project on the Precidament of Mankind. New York: Universe Books.

Messner, S., and Strubegger, M. (1995). User's Guide for MESSAGE III, WP-95-69. Vienna: IAASA.

Nakicenovic, N., and Swart, R. (2000). Special Report on Emissions Scenarios: A Special Report of Working Group III of the Intergovernmental Panel on Climate Change. Cambridge: Cambridge University Press.

Nilsson, M., Nilsson, L. J., Hildingsson, R., Stripple, J., and Eikeland, P. O. (2011). The missing link: bringing institutions and politics into energy future studies. Futures 43, 1117-1128. doi:10.1016/j.futures.2011.07.010

Nordhaus, W. D., and Boyer, J. (2000). Warning the World: Economic Models of Global Warming. Cambridge: MIT Press.

Nygren, E., Aleklett, K., and Höök, M. (2009). Aviation fuel and future oil production scenarios. Energy Policy 37, 4003-4010. doi:10.1021/es202148g

Peng, R. D. (2011). Reproducible research in computational science. Science 334, 1226-1227. doi:10.1126/science.1213847

Proença, S., and St. Aubyn, M. (2013). Hybrid modeling to support energy-climate policy: effects of feed-in tariffs to promote renewable energy in Portugal. Energy Econ. 38, 176-185. doi:10.1016/j.eneco.2013.02.013

Randall, D. A., and Wood, R. A. (2007). "Climate models and their evaluation," in Climate Change 2007: The Physical Science Basis. Contribution of Working Group I to the Fourth Assessment Report of the Intergovernmental Panel on Climate Change, ed. Intergovernmental Panel of Climate Change (Cambridge: Cambridge University Press), 589-662.
Rifkin, J., and Howard, T. (1980). Entropy: A New World View. New York: Viking Adult.

Sabatier, P. A. (1988). An advocacy coalition framework of policy change and the role of policy-oriented learning therein. Policy Sci. 21, 129-168. doi:10.1007/ BF00136406

Sambo, A. S. (2008). Matching Electricity Supply with Demand in Nigeria. IAEE Energy Forum (Newsletter) Fourth Quarter (Cleveland: International Association for Energy Economics), 32-36.

Sassi, O., Crassous, R., Hourcade, J. C., Gitz, V., Waisman, H., and Guivarch, C. (2010). IMACLIM-R: a modelling framework to simulate sustainable development pathways. Int. J. Global Environ. Issues 10, 5-24. doi:10.1504/IJGENVI. 2010.030566

Schwab, M., Karrenbach, N., and Claerbout, J. (2000). Making scientific computations reproducible. Comput. Sci. Eng. 2, 61-67.

Seebregts, A. J., Goldstein, G. A., and Smekens, K. (2001). Energy/environmental modeling with the MARKAL family of models. Operations Research Proceedings 2001 (Duisburg: Springer), 75-82.

Stodden, V. C. (2010). Reproducible research: addressing the need for data and code sharing in computational science. Comput. Sci. Eng. 12, 8-12.

van Beeck, N. (1999). Classification of Energy Models [WWW Document]. FEW 777, Research Memorandum. Available at: http://arno.uvt.nl/show.cgi?fid=3901 [accessed 8, 11, 13].

Varum, C. A., and Melo, C. (2010). Directions in scenario planning literature - a review of the past decades. Futures 42, 355-369. doi:10.1016/j.futures.2009.11. 021

Volkery, A., and Ribeiro, T. (2009). Scenario planning in public policy: understanding use, impacts and the role of institutional context factors. Technol. Forecast. Soc. Change 76, 1198-1207. doi:10.1016/j.techfore.2009.07.009

Walras, L. (1954). Elements of Pure Economics: Or the Theory of Social Wealth. Lausanne: Routledge.

Walz, A., Lardelli, C., Behrendt, H., Grêt-Regamey, A., Lundström, C., Kytzia, S., et al. (2007). Participatory scenario analysis for integrated regional modelling. Landsc. Urban Plan. 81, 114-131. doi:10.1016/j.landurbplan.2006.11.001

Conflict of Interest Statement: The authors declare that the research was conducted in the absence of any commercial or financial relationships that could be construed as a potential conflict of interest.

Received: 14 September 2013; paper pending published: 10 October 2013; accepted: 23 December 2013; published online: 13 January 2014.

Citation: Benichou L and Mayr S (2014) Rogeaulito: A World Energy Scenario Modeling Tool for Transparent Energy System Thinking. Front. Energy Res. 1:13. doi: 10.3389/fenrg.2013.00013

This article was submitted to Energy Systems and Policy, a section of the journal Frontiers in Energy Research.

Copyright (c) 2014 Benichou and Mayr. This is an open-access article distributed under the terms of the Creative Commons Attribution License (CC BY). The use, distribution or reproduction in other forums is permitted, provided the original author (s) or licensor are credited and that the original publication in this journal is cited, in accordance with accepted academic practice. No use, distribution or reproduction is permitted which does not comply with these terms. 